\title{
POTENTIALS OF THE WASTE-TO-ENERGY SECTOR FOR AN UNCONVENTIONAL DISTRICT HEATING SYSTEM
}

\author{
MARCO RAGAZZI ${ }^{1}$, KEVIN FERRARI $^{1}$, LUCA ADAMI $^{1}$, MARCO SCHIAVON $^{1} \&$ \\ ELENA CRISTINA RADA ${ }^{2}$ \\ ${ }^{1}$ University of Trento, Department of Civil, Environmental and Mechanical Engineering, Trento, Italy. \\ ${ }^{2}$ University of Insubria, Department of Theoretical and Applied Sciences, Varese, Italy.
}

\begin{abstract}
In spite of being a process that exploits a renewable source of energy, the combustion of wood-based biomass contributes to deteriorate outdoor and indoor air quality. Critical situations for human exposure may occur in mountainous areas, where wood-based biomass is usually abundant and the complex morphology may favour the stagnation of air pollutants in valleys. Replacing wood/pellet stoves with centralised systems would reduce the impact, but the construction of district heating systems may not be convenient in areas with low density of houses. A possible solution could rely on direct electrical heating (DEH) systems, preferably fed by thermochemical processes that help achieve environmental goals for the local community, like the reduction of waste landfilling and the valorisation of the energy content of waste. This paper aims at presenting a comparison between the impacts expected by household wood/pellet stoves and by a modern waste-to-energy (WtE) plant, in terms of emissions of air pollutants into the atmosphere, when replacing wood stoves with a DEH system fed by the electric energy generated by the WtE plant. The comparison shows that the replacement of household stoves with an equivalent DEH system would be beneficial in terms of impacts on the local air quality. Such an approach could be considered to reduce the health impacts from biomass burning in critical areas like the Alpine region.
\end{abstract}

Keywords: biomass burning, dispersion, electrical radiators, environmental sustainability, gasification, road transport, waste management.

\section{INTRODUCTION}

The Alpine region is a mountainous area shared by several European nations (Italy, France, Switzerland, Austria, Slovenia, Liechtenstein and Germany) that is characterised by peculiar climate and meteorological conditions $[1,2]$ and that has developed a strong tourist vocation over the last decades [3-5]. The presence of numerous valleys, differently oriented, creates local conditions of wind circulation, atmospheric stability, solar heating and mean daily/monthly cycles of temperature, which concur to create specific situations for the dispersion of air pollutants in the atmosphere and, consequently, air quality conditions that may be critical to residents [6-8]. In general, valleys tend to accumulate the air pollutants that are generated within, due to frequent episodes of thermal inversion, which occur more often during the winter season because of the lower solar irradiation [9]. Consequently, the solidand gaseous-phase air pollutants released by road traffic and both industrial and civil activities may concentrate at the bottom of valleys, where the majority of the population lives, and this increases the overall human exposure to air pollution [10-13].

Contrarily to industrial activities or large civil plants, which are strictly monitored emission sources complying with specific environmental regulations, the control of road traffic and small civil activities is more difficult, due to the multitude of single emission sources and to less stringent emission limits and monitoring requirements. Among small civil activities, domestic heating is one of the most difficult to control, since household boilers may be fed with different fuel (whose combustion entails different impacts on air quality) are subject to operation modes that depend on the behaviour of each family and release the exhaust air at a 
lower height and with a lower outlet velocity with respect to industrial activities and centralised heating plants [14].

Being primarily used in developing countries as a source of energy for space heating and for cooking, wood-based biomass has recently encountered a rapid growth in terms of usage even in developed countries [15]. Reasons for that may be the increase of the cost of fossil fuel and the recent global economic crisis [16-17], which induced the population to purchase a cheaper fuel like wood-based biomass (i.e. firewood and pellets). The Alpine region is rich in forests and this makes wood-based biomass an abundant resource available to the population that lives in this area.

The combustion of wood-based biomass does not generate positive contributions of greenhouse gases (GHGs) in the atmosphere, since this process is based on the combustion of a biogenic source of carbon. This aspect allows considering wood-based biomass as a sustainable source of energy. Such a conclusion should anyway consider the potential GHG emissions from the wood supply chain (e.g. the cutting of trees, road transport and artificial wood drying). However, although the null or very low contribution in terms of its global impact, wood burning is a known source of several air pollutants that may concur to create critical conditions for the air quality of delicate morphological contexts like mountainous regions. Specifically, wood combustion is responsible for the emission of sulphur and nitrogen oxides $\left(\mathrm{SO}_{x}\right.$ and $\mathrm{NO}_{x}$, respectively), carbon monoxide $(\mathrm{CO})$, volatile organic compounds (VOCs), ammonia $\left(\mathrm{NH}_{3}\right.$ ), metals, polycyclic aromatic hydrocarbons (PAHs), dioxin and, generally, particulate matter (PM) [18-22].

The recent diffusion of centralised biomass thermal plants for district heating in Alpine villages would help reduce local impacts, since centralised plants are monitored emission sources, equipped with state-of-the-art air pollution treatment systems, contrarily to domestic stoves [15-23]. However, an interesting opportunity comes from the achievement of another need, i.e. the optimisation of waste management in the area. Indeed, in a perspective of circular economy, governments must implement actions to close the loop of waste, by maximising the achievement of the targets stated by the so-called "4 Rs" (reduction, reuse, recycling and recovery), and minimising the disposal of waste into landfills. To this purpose, $\mathrm{WtE}$ processes, if optimised in terms of pollutant emissions, energy recovery and recycling of waste products, play a fundamental role in sustainable waste management [24, 25]. Specifically, WtE processes allow reducing the amount of waste sent to landfills, obtaining electric and thermal energy from the combustion of waste and, in some cases, recycling the bottom ashes as a material for the field of construction. The thermal energy generated by a WtE plant could then be employed to feed a district heating (DH) network, if a sufficiently dense urbanised area is present nearby [26]. However, usually this is not the case of Alpine contexts, where villages and small towns are more common.

An interesting alternative to the conventional DH is represented by the so-called direct electrical heating (DEH), which consists in heating systems based on heat pumps or electric radiators instead of using warm water in traditional radiators. Thus, a WtE plant, in addition to playing a key role in waste management, would allow providing small communities with energy for space heating and electrical appliances, whereas conventional DH systems would not be applicable and in place of more polluting household heating systems.

Considering that, the present paper is intended to estimate and compare the potential impacts of domestic wood/pellet stoves with those expected from a WtE plant in terms of emissions of air pollutants into the atmosphere. This paper will present the case of a small village located in an Alpine region, where the waste is carried outward to two WtE plants and wood-based biomass is commonly used as a source for space heating. The present situation 
will be compared with a possible future scenario consisting in the construction of a WtE plant allowing for electric energy production and in the use of electric radiators by the local population, instead of wood/pellet stoves. Such a comparison represents a matter of novelty in the field and may pave the road to deeper analyses on the environmental and economical convenience of different heat supply systems.

\section{MATERIAL AND METHODS}

The area of study is a village with 2,205 inhabitants located at the bottom of an Alpine valley, oriented North-South. According to local statistics, the whole population of the region where the village is located $(510,640$ inhabitants in 2013) consumes, respectively, 312,741 t/y and $36,185 \mathrm{t} / \mathrm{y}$ of wood and pellet for heating purposes [27]. The consumption of wood and pellet in the village may be estimated by a proportion between the population of the whole province and the residents in the village, by assuming that the per-capita wood and pellet consumption did not vary in the last years. Thus, the residents in the village would use 1,355 t/y and $156 \mathrm{t} / \mathrm{y}$ of wood and pellet, respectively. Considering that a family unit is composed of about 2.4 persons, each family unit would burn, on average, $1.48 \mathrm{t} / \mathrm{y}$ of wood and $0.17 \mathrm{t} / \mathrm{y}$ of pellet.

The WtE plant would allow treating about 95,000 t/y of refuse-derived fuel and other waste. In the current situation, such amount of waste is carried away from the region by trucks to other WtE plants, located $180-\mathrm{km}$ and $325-\mathrm{km}$ far from the potential site for the plant construction. The WtE plant under evaluation would carry out an indirect combustion of waste, specifically a gasification process. The plant would be operating for 7,500 h/y and would be able to generate about $100 \mathrm{GWh} /$ year of electric energy. The plant would use improved air pollution control technologies to ensure concentration values of the air pollutants at the stack far lower than the limit values established by the European environmental legislation [28]. The exhaust gas flow rate is expected to be equal to $107,000 \mathrm{Nm}^{3} / \mathrm{h}$, with an oxygen content of $6.4 \%$.

An aerial view of the area is presented in Fig. 1.

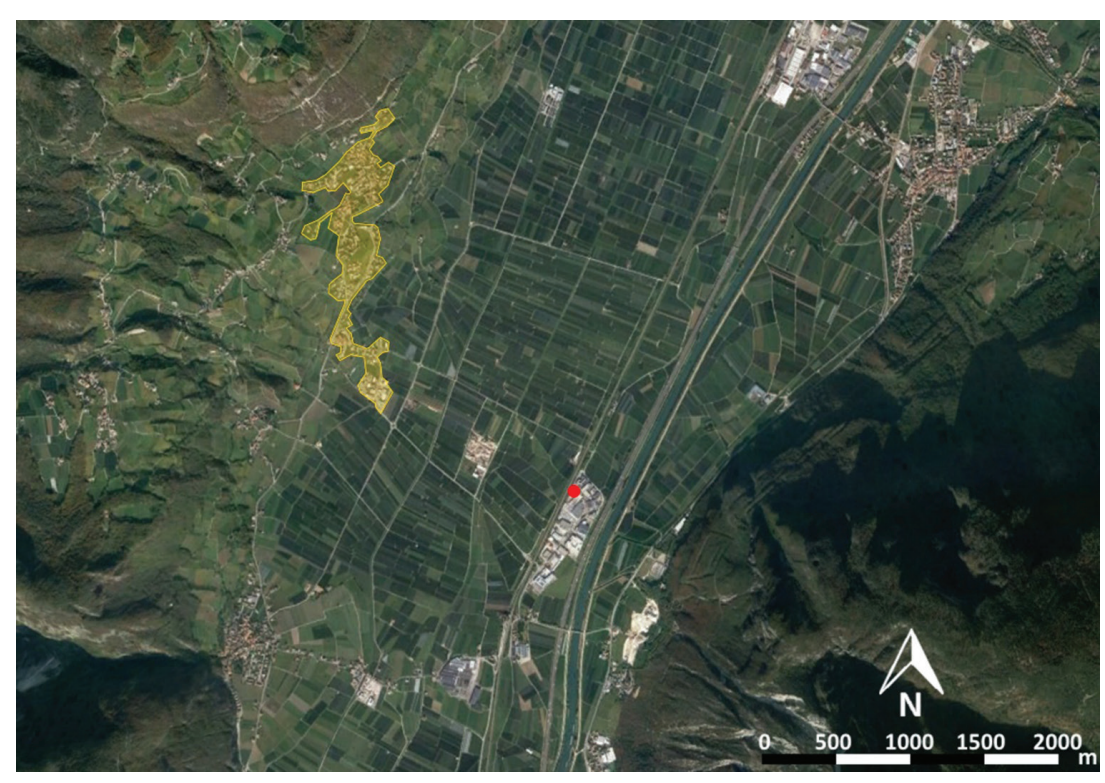

Figure 1: Location of the village (yellow area) and of the hypothetical WtE plant (red circle) [29]. 
Due to the low demographic density of the area, a conventional DH would not be applicable [26]. Therefore, two scenarios will be compared:

- a present-case scenario, which considers the combustion of wood-based biomass by the local population and the transportation of waste to the current destinations;

- a future scenario, which assumes that the electric and thermal demand by the local population is totally covered by the electric energy produced by the WtE plant.

In this last case, thermal energy would be provided by electric heaters via a so-called direct electric heating $(\mathrm{DEH})$ system.

To comply with the European environmental legislation, the WtE plant must comply with concentration limit values for the following air pollutants: total suspended particles (TSP), $\mathrm{NO}_{x}$, sulphur dioxide $\left(\mathrm{SO}_{2}\right), \mathrm{CO}$, hydrochloric acid $(\mathrm{HCl})$, hydrofluoric acid $(\mathrm{HF}), \mathrm{NH}_{3}$, total organic carbon (TOC), PAHs, dioxins and furans (PCDD/Fs), polychlorinated biphenyls (PCBs), cadmium and thallium $(\mathrm{Cd}+\mathrm{Tl})$, mercury $(\mathrm{Hg})$ and other heavy metals [28]. To obtain the emission values of these pollutants, the concentration values must be corrected by considering their normalisation to the oxygen content of the exhaust gas and multiplied by the gas flow rate. The results of this calculation will be presented in Section 3, together with the mass flow rates deriving from the sources considered in the present case (road transport and stoves burning wood-based biomass).

The second term of comparison is represented by the current situation, where wood-based biomass is used by the local population for heating purposes and the waste is transported outward to the two aforementioned WtE plants. The calculation of the emissions from those sources can be carried out by the adoption of appropriate emission factors available in the literature. A complete and updated emission inventory is provided by the European Environment Agency (EEA) [30]. To calculate the emission values, the emission factors must multiply the biomass consumption rate and the lower heating value (LHV) of the biomass type considered. LHVs of $14.7 \mathrm{MJ} / \mathrm{kg}$ and $17.3 \mathrm{MJ} / \mathrm{kg}$ were assumed for wood and pellets, according to the indications of the EEA [30].

The emission factors for road transport were retrieved from the same database, by assuming that the waste transportation is carried out by 26-t trucks complying with the latest emission standard (EURO VI) [31]. Such trucks are able to carry $16 \mathrm{t}$ of material. Slope effects were not used. Considering slope effects as null on a return trip from/to an elevated origin/destination would be erroneous, since a rise generates higher pollutant emissions and fuel consumption than how much a descent would allow saving [32]. However, such a simplification would lead to precautionary results in view of a comparison between current and future scenarios, since it would underestimate the impacts of the present situation.

In order to compare the different scenarios, the air pollutants and their categories must be re-arranged, since different sources consider different pollutants and different levels of aggregation. Specifically, the following steps are necessary:

- the $\mathrm{SO}_{x}$ emission factor from stoves must be assumed as a $\mathrm{SO}_{2}$ emission factor;

- the emission factor of fine PM (PM2.5) from trucks must be assumed as a TSP emission factor;

- the TOC concentration value at the stack of the WtE plant must be assumed as a VOC concentration;

- heavy metals must be aggregated as a group and the single emission factors (or stack concentrations for the WtE plant) must be summed up; 
Table 1: Emission factors for wood/pellet stoves and road traffic (present case), and stack concentration values ensured by the WtE plant (future scenario).

\begin{tabular}{lcccc}
\hline & & Present case [30] & $\begin{array}{c}\text { Road } \\
\text { transportation } \\
\text { of waste }\end{array}$ & Wuture scenario \\
Air pollutants & $\begin{array}{c}\text { Wood stoves } \\
\text { [g/GJ] }\end{array}$ & $\begin{array}{c}\text { Pellet stoves } \\
{[\mathbf{g} / \mathbf{G J}]}\end{array}$ & $\begin{array}{c}\text { [g/km] } \\
\text { Nm}^{3} \text { ] }\end{array}$ \\
\hline TSP & 800 & 62 & 0.0013 & 1.5 \\
$\mathrm{NO}_{x}$ & 50 & 80 & 0.422 & 40 \\
$\mathrm{SO}_{2}$ & 11 & 11 & 0.0034 & 10 \\
$\mathrm{CO}$ & 4,000 & 300 & 0.105 & 50 \\
$\mathrm{NH}_{3}$ & 70 & 12 & 0.011 & 10 \\
VOCs & 600 & 10 & 0.01 & 10 \\
Heavy metals & $5.8 \cdot 10^{-3}$ & $5.8 \cdot 10^{-3}$ & $8.1 \cdot 10^{-6}$ & 0.3 \\
PAHs & 0.345 & 0.035 & $2.4 \cdot 10^{-4}$ & 0.01 \\
PCDD/Fs & $8 \cdot 10^{-7}$ & $1 \cdot 10^{-7}$ & $7.4 \cdot 10^{-13}$ & $2.5 \cdot 10^{-8}$ \\
PCBs & $6 \cdot 10^{-8}$ & $1 \cdot 10^{-8}$ & $1.5 \cdot 10^{-13}$ & $1 \cdot 10^{-7}$ \\
\hline
\end{tabular}

${ }^{*}$ Mass values expressed as I-TEQ.

- emissions of $\mathrm{HCl}$ and $\mathrm{HF}$ from the WtE must be neglected from the scenario comparison, since no emission factors are reported for biomass burning and road transport.

In view of a comparison between the two scenarios, the first three assumptions may lead to an underestimation of the current impacts. The concentration values ensured by the WtE plant, the emission factors for wood and pellet stoves and those related to road transport are presented in Table 1, according to the new arrangement of the air pollutants for a comparison between the two scenarios.

\section{RESULTS AND DISCUSSION}

The emissions from the three categories of sources (WtE plant, biomass burning and road transport) for the case study under investigation are reported in Table 2. The emissions from the WtE plant are calculated on the basis of the exhaust gas flow rate and on the stack concentration values normalised to the oxygen content. The emissions from road transport consider the distance covered by the number of round trips necessary to ship 95,000 t/y of waste to the two current destinations (mean round-trip distance: $505 \mathrm{~km}$ ). The emissions from biomass burning consider the average amount of wood and pellet burnt annually only by the population of the village.

As shown in Table 2 the replacement of the stoves with a DEH system, if limited only to the population of the nearest village, would bring improvements in terms of air pollutant emissions only with regards to TSP, CO and VOCs. Significant improvements would be obtained by exploiting all the potential electric energy produced by the $\mathrm{WtE}$ plant, i.e. by extending the DEH system to all the users whose energy demand could be covered by the 
Table 2: Mass flow rates ( $\mathrm{t} / \mathrm{y}$ ) of air pollutants from wood-based biomass burning and road traffic (present case), and from the WtE plant (future scenario) referred only to the village under investigation.

\begin{tabular}{|c|c|c|c|c|}
\hline Air pollutants & Stoves & $\begin{array}{c}\text { Present case } \\
\text { Road transportation } \\
\text { of waste }\end{array}$ & Total & Future scenario \\
\hline TSP & 16.06 & $3.9 \cdot 10^{-3}$ & 16.06 & 1.76 \\
\hline $\mathrm{NO}_{x}$ & 1.21 & 1.27 & 2.48 & 46.87 \\
\hline $\mathrm{SO}_{2}$ & 0.25 & 0.01 & 0.26 & 58.58 \\
\hline $\mathrm{CO}$ & 80.27 & 0.31 & 80.58 & 11.72 \\
\hline $\mathrm{NH}_{3}$ & 1.42 & 0.03 & 1.45 & 11.72 \\
\hline VOCs & 11.95 & 0.03 & 11.98 & 11.72 \\
\hline Heavy metals & $2.4 \cdot 10^{-5}$ & $1.3 \cdot 10^{-4}$ & $1.5 \cdot 10^{-4}$ & 0.35 \\
\hline PAHs & 0.01 & $7.3 \cdot 10^{-4}$ & 0.01 & 0.01 \\
\hline PCDD/Fs* & $1.62 \cdot 10^{-8}$ & $2.22 \cdot 10^{-12}$ & $1.62 \cdot 10^{-8}$ & $2.93 \cdot 10^{-8}$ \\
\hline PCBs & $1.22 \cdot 10^{-9}$ & $4.50 \cdot 10^{-13}$ & $1.22 \cdot 10^{-9}$ & $1.17 \cdot 10^{-7}$ \\
\hline
\end{tabular}

${ }^{*}$ Mass values expressed as I-TEQ.

capacity of the plant in terms of electric energy (100 GWh/y). According to local statistics [27], the average electric energy consumption for lights and electrical appliances per family unit is about 2,100 kWh/y. A house located in an Alpine valley, with a medium class of energy efficiency, can require $90 \mathrm{kWh} / \mathrm{m}^{2} / \mathrm{y}$ of thermal energy for heating. By assuming a $100-\mathrm{m}^{2}$ flat and considering that heat is provided by electric heaters with $100 \%$ energy efficiency, the total electric energy consumption would be $11,100 \mathrm{kWh} / \mathrm{y}$ per family, including the energy consumption for lights and appliances. The $\mathrm{WtE}$ plant would then be able to cover, on average, the electric energy demand of about 9,000 family units, which could then convert their heating system from a wood-based biomass stove to electric heaters. This way, the future scenario can be compared with a present-case scenario which considers 9,000 families using wood-based biomass for heating, instead of the 913 families of the single village (Table 3 ).

The improvements, in terms of the emission balance, are visible, even though the future scenario emits higher amounts of $\mathrm{NO}_{x}, \mathrm{SO}_{2}$, heavy metals and PCBs than the present case. However, from the point of view of human health, ambient air concentrations are relevant, contrarily to

Table 3: Mass flow rates ( $t / y)$ of air pollutants from wood-based biomass burning and road traffic (present case), and from the WtE plant (future scenario) referred to all the potential users of the DEH system.

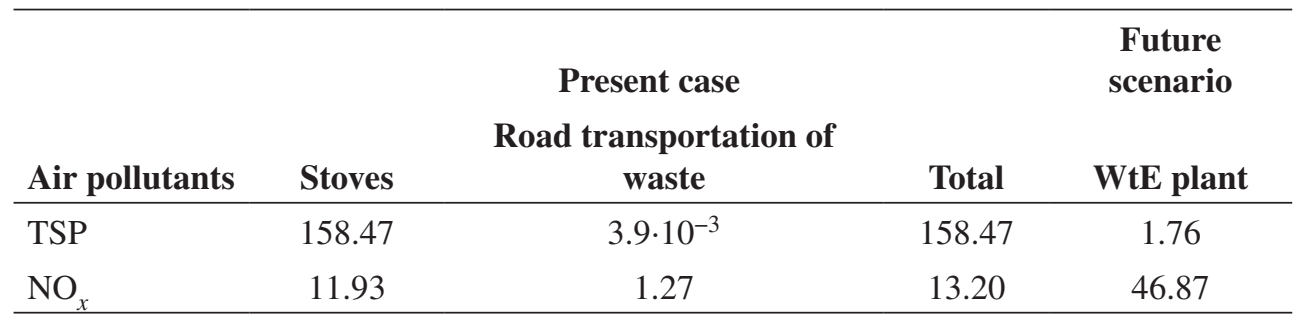




\begin{tabular}{lcccc}
\hline $\mathrm{SO}_{2}$ & 2.45 & 0.01 & 2.46 & 58.58 \\
$\mathrm{CO}$ & 792.07 & 0.31 & 792.38 & 11.72 \\
$\mathrm{NH}_{3}$ & 14.04 & 0.03 & 15.46 & 11.72 \\
$\mathrm{VOCs}$ & 117.88 & 0.03 & 117.91 & 11.72 \\
Heavy metals & $1.3 \cdot 10^{-3}$ & $1.3 \cdot 10^{-4}$ & $1.4 \cdot 10^{-3}$ & 0.35 \\
$\mathrm{PAHs}$ & 0.07 & $7.3 \cdot 10^{-4}$ & 0.07 & 0.01 \\
$\mathrm{PCDD} / \mathrm{Fs}^{*}$ & $1.6 \cdot 10^{-7}$ & $2.22 \cdot 10^{-12}$ & $1.6 \cdot 10^{-7}$ & $2.93 \cdot 10^{-8}$ \\
$\mathrm{PCBs}$ & $1.2 \cdot 10^{-8}$ & $4.50 \cdot 10^{-13}$ & $1.2 \cdot 10^{-8}$ & $1.17 \cdot 10^{-7}$ \\
\hline
\end{tabular}

* Mass values expressed as I-TEQ.

emissions. It is important to consider the dilution effect ensured by a 45-m stack, with respect to the chimneys of the houses, could be higher by some orders of magnitude. Thus, the impact of a WtE plant on the local air quality could be far lower than the impacts of wood biomass burning.

\section{CONCLUSIONS}

The comparison carried out in this paper showed the environmental advantages that DEH would involve when replacing household wood/pellet stoves. When considering a WtE plant as the source of electric energy for a DEH system, an overall reduction of the total emissions of several air pollutants (TSP, CO, VOCs, $\mathrm{NH}_{3}$, PAHs and PCDD/Fs) can be achieved. On the other hand, higher mass flow rates are estimated for $\mathrm{NO}_{x}, \mathrm{SO}_{2}$, metals and PCBs when considering the DEH. However, the release mode of the chimneys of dwellings is considerably different from the release of the exhaust gas from a WtE plant. The higher elevation of the stacks of WtE plants (tens of meters) and the outlet velocity of the exhaust gas (usually a few of tens of $\mathrm{m} / \mathrm{s}$ ) allow for a better dilution of the plume with respect to household stoves. Consequently, the overall impact on the air quality is expected to be lower by some orders of magnitude when replacing a multitude of single wood/pellet stoves with a centralised plant like a state-of-the-art waste combustor. DEH could replace/integrate also conventional DH systems in areas where the latter are not convenient, due to the low density of houses. This approach would be beneficial to the air quality of specific geographical contexts where the use of wood-based biomass for space heating is abundant, like in Alpine valleys, and would exploit an important step of sustainable waste management, i.e. WtE processes.

\section{REFERENCES}

[1] Tomasi, E., Antonacci, G., Giovannini, L., Zardi, D. \& Ragazzi, M., Atmospheric dispersion modelling with AERMOD for comparative impact assessment of different pollutant emission sources in an alpine valley. WIT Transactions on Ecology and the Environment, 198, WIT Press: Southampton and Boston, pp. 431-442, 2015. https:// doi.org/10.2495/air150371

[2] Li, Y., Campana, M., Reimann, S., Schaub, D., Stemmler, K., Staehelin, J. \& Peter, T., Hydrocarbon concentrations at the Alpine mountain sites Jungfraujoch and Arosa. Atmospheric Environment, 39(6), pp. 1113-1127, 2005. https://doi.org/10.1016/j. atmosenv.2004.09.084

[3] Gerber, J.D. \& Bandi Tanner, M., The role of Alpine development regimes in the development of second homes: Preliminary lessons from Switzerland. Land Use Policy, 77, pp. 859-870, 2018. https://doi.org/10.1016/j.landusepol.2017.09.017 
[4] Zoderer, B.M., Tasser, E., Erb, K.H., Lupo Stanghellini, P.S. \& Tappeiner, U., Identifying and mapping the tourists' perception of cultural ecosystem services: A case study from an Alpine region. Land Use Policy, 56, pp. 251-261, 2016. https://doi. org/10.1016/j.landusepol.2016.05.004

[5] Ranieri, E., Rada, E.C., Ragazzi, M., Masi, S. \& Montanaro, C., Critical analysis of the integration of residual municipal solid waste incineration and selective collection in two Italian tourist areas. Waste Management and Resources, 32(6), pp. 551-555, 2014. https://doi.org/10.1177/0734242x14533605

[6] Laiti, L., Giovannini, L., Zardi, D., Belluardo, G. \& Moser, D., Estimating hourly beam and diffuse solar radiation in an alpine valley: A critical assessment of decomposition models. Atmosphere, 9(4), p. 117, 2018. https://doi.org/10.3390/atmos9040117

[7] Zardi, D., Mountain meteorology: Valley winds. Encyclopedia of Atmospheric Sciences, eds. G. North, J. Pyle \& F. Zhang, 2nd edn., Academic Press, pp. 114-134, 2014. https:// doi.org/10.1016/b978-0-12-382225-3.00240-1

[8] Curci, G., Cinque, G., Tuccella, P., Visconti, G., Verdecchia, M., Iarlori, M. \& Rizi, V., Modelling air quality impact of a biomass energy power plant in a mountain valley in Central Italy. Atmospheric Environment, 62, pp. 248-255, 2012. https://doi. org/10.1016/j.atmosenv.2012.08.005

[9] Argentini, S., Pietroni, I., Mastrantonio, G., Viola, A.P., Dargaud, G. \& Petenko I., Observations of near surface wind speed, temperature and radiative budget at Dome $\mathrm{C}$, Antarctic Plateau during 2005. Antarctic Science, 26(1), pp. 104-112, 2013. https://doi. org/10.1017/s0954102013000382

[10] Bertolotti, G., Rada, E.C., Ragazzi, M., Chisté, A. \& Gialanella, S., A multi-analytical approach to the use of conifer needles as passive samplers of particulate matter and organic pollutants. Aerosol and Air Quality Research, 14(3), pp. 677-685, 2014. https:// doi.org/10.4209/aaqr.2013.10.0308

[11] Hazenkamp-Von Arx, M.E., Schindler, C., Ragettli, M.S., Künzli, N. Braun-Fahrländer, C. \& Liu, L.J.S., Impacts of highway traffic exhaust in alpine valleys on the respiratory health in adults: A cross-sectional study. Environmental Health: A Global Access Science Source, 10(1), p. 13, 2011. https://doi.org/10.1186/1476-069x-10-13

[12] Pognant, F., Bo, M., Nguyen, C.V., Salizzoni, P. \& Clerico, M., Modelling and evaluation of emission scenarios deriving from wood biomass boilers in alpine valley. Proceedings of HARMO 2017-18th International Conference on Harmonisation within Atmospheric Dispersion Modelling for Regulatory Purposes, pp. 278-282, 2017.

[13] Largeron, Y. \& Staquet, C., Persistent inversion dynamics and wintertime PM10 air pollution in Alpine valleys. Atmospheric Environment, 135, pp. 92-108, 2016. https://doi. org/10.1016/j.atmosenv.2016.03.045

[14] Paradiž, B., Dilara, P., .Horák, J., De Santi, G., Christoph, E.H. \& Umlauf, G., An integrated approach to assess the PCDD/F emissions of the coal fired stoves combining emission measurements and ambient air levels modelling. Chemosphere, 73(1), pp. S94-S100, 2008. https://doi.org/10.1016/j.chemosphere.2007.12.039

[15] Schiavon, M., Ragazzi, M., Rada, E.C., Magaril, E. \& Torretta, V., Towards a sustainable management of air quality and human exposure: exemplary case studies. WIT Transactions on Ecology and the Environment, vol. 230, WIT Press: Southampton and Boston, pp. 489-500, 2018.

[16] Frasca, D., Marcoccia, M., Tofful, L., Simonetti, G., Perrino, C. \& Canepari, S., Influence of advanced wood-fired appliances for residential heating on indoor air quality. Chemosphere, 211,pp.62-71,2018. https://doi.org/10.1016/j.chemosphere.2018.07.102 
[17] Rao, M., D'Elia, I. \& Piersanti, A., An uncertainty quantification of PM2.5 emissions from residential wood combustion in Italy. Atmospheric Pollution Research, 9(3), pp. 526-533, 2018. https://doi.org/10.1016/j.apr.2017.12.002

[18] Zielinska, B. \& Samburova, V., Residential and Non-Residential Biomass Combustion: Impacts on Air Quality. Encyclopedia of Environmental Health, ed. J.O. Nriagu, Elsevier Science: Burlington, pp. 819-827, 2011. https://doi.org/10.1016/b978-0-44452272-6.00368-8

[19] Williams, A., Jones, J.M., Ma, L. \& Pourkashanian, M., Pollutants from the combustion of solid biomass fuels. Progress in Energy and Combustion Science, 38(2), pp. 113-137, 2012. https://doi.org/10.1016/j.pecs.2011.10.001

[20] Mitchell, E.J.S., Coulson, G., Butt, E.W., Foster, P.M., Jones, J.M. \& Williams, A., Heating with Biomass in the United Kingdom: Lessons from New Zealand. Atmospheric Environment, 152, pp. 431-454, 2017. https://doi.org/10.1016/j.atmosenv.2016.12.042

[21] Sinha, S.N. \& Nag, P.K., Air Pollution From Solid Fuels. Encyclopedia of Environmental Health, ed. J.O. Nriagu, Elsevier Science: Burlington, pp. 46-52, 2011. https://doi. org/10.1016/b978-0-444-52272-6.00694-2

[22] Schiavon, M., Torretta, V., Rada, E.C. \& Ragazzi, M., State of the art and advances in the impact assessment of dioxins and dioxin-like compounds. Environmental Monitoring and Assessment, 188(1), pp. 1-20, 2016. https://doi.org/10.1007/s10661-015-5079-0

[23] Giurea, R., Precazzini, I., Ragazzi, M. \& Achim, M.I., Criteria for environmental optimization of electrical and thermal energy in agro-tourism. WIT Transactions on Ecology and the Environment, vol. 224, WIT Press: Southampton and Boston, pp. 317-319, 2017. https://doi.org/10.2495/esus170301

[24] Rada, E.C., Ragazzi, M., Ionescu, G., Merler, G., Moedinger, G., Raboni, M. \& Torretta, V., Municipal Solid Waste treatment by integrated solutions: Energy and environmental balances. Energy Procedia, 50, pp. 1037-1044, 2014. https://doi. org/10.1016/j.egypro.2014.06.123

[25] Rada, E.C., Ragazzi, M., Torretta, V., Castagna, G., Adami, L. \& Cioca, L.I., Circular economy and waste to energy. AIP Conference Proceedings, 1968(1), p. 030050, 2018. https://doi.org/10.1063/1.5039237

[26] Werner, S., International review of district heating and cooling. Energy, 137, pp. 617-631, 2017. https://doi.org/10.1016/j.energy.2017.04.045

[27] Statistiche Istat, National Institute of Statistics (in Italian), http://dati.istat.it/ (accessed 4 February 2019).

[28] European Union, Directive 2010/75/EU of the European Parliament and of the Council of 24 November 2010 on industrial emissions (integrated pollution prevention and control). Official Journal of the European Union, Document 32010L0075.

[29] Google Maps, https://maps.google.com/

[30] European Environment Agency, EMEP/EEA air pollutant emission inventory guidebook 2016-Last Update June 2017. Technical report, 2017.

[31] European Union, 2011. Commission Regulation (EU) No 582/2011 of 25 May 2011 implementing and amending Regulation (EC) No 595/2009 of the European Parliament and of the Council with respect to emissions from heavy duty vehicles (Euro VI) and amending Annexes I and III to Directive 2007/46/EC of the European Parliament and of the Council. Official Journal of the European Union, Document 32011R0582.

[32] COPERT download; EMISIA, https://copert.emisia.com/ (accessed 6 February 2019). 